\title{
Control Charts to Support Trust Monitoring in Dynamic Logistics Networks
}

\author{
António Abreu ${ }^{1,2}$, José Requeijo ${ }^{3}$, J. M. F. Calado ${ }^{1,4}$, Ana Dias ${ }^{1}$ \\ ${ }^{1}$ ISEL- Instituto Superior de Engenharia de Lisboa, Instituto Politécnico de Lisboa \\ ${ }^{2}$ Uninova Institute, Centre of Technology and Systems, Portugal \\ ${ }^{3}$ UNIDEMI/SEM, Systems Engineering and Management, Portugal \\ ${ }^{4}$ IDMEC-LAETA-IST-UL Lisboa, Portugal \\ ajfa@dem.isel.ipl.pt,jfgr@fct.unl.pt, jcalado@dem.isel.ipl.pt, asdias@dem.isel.ipl.pt
}

\begin{abstract}
Nowadays, companies to be competitive must develop capabilities that enable them to respond quickly to market needs. According to some managers, the strategy is the development of dynamic logistics networks based on a collaborative environment. However, the absence of mechanisms to detect and even anticipate potential opportunistic behaviour is an obstacle to the proliferation of this way of working. The article aims to understand the role of trust to sustainability of collaborative processes. The paper begins by discussing the trust properties. It is then discussed how statistical control charts can be used to support the trust monitoring of each member within a collaborative ecosystem. The control charts' tools suggested in this paper are the $\mathrm{Z}$ control charts for trust level monitoring and the $\mathrm{Zi}$ capacity index. Finally, it is discussed how this approach can be applied to dynamic logistics networks within the context of a collaborative ecosystem.
\end{abstract}

Keywords: Trust, Logistic, Quality, Collaborative networks, Management

\section{Introduction}

Nowadays, in order to strengthen competitiveness, companies have to start learning to join forces in certain areas or competencies, and may wish to follow different paths in others, through the dynamization of intercompany relationships, giving rise to organizational models based on collaboration networks between companies [1].

With the rapid development of the technologies associated with the industrial revolution 4.0, in particular the information technologies and technologies associated with the Internet of Things (IoT), some authors defend the sustainability of new models which led to a proliferation of new designations such as the notion of virtual company / virtual organization, collaborative supply chain, Dynamic Supply Chain, Lean Supply Chain, among others [2 -4]. Thus, the concept of dynamic logistics network should not be interpreted as a totally new model of cooperation, but as a process of evolution of traditional logistics networks, induced by the development of technology. The concept of dynamic logistics network is related to a temporary network of companies, which is quickly formed to exploit a business opportunity in response to a market request and dissolves when its initial mission is achieved.

However, the relationships established between companies in a logistics network are not only relationships of buying and selling products or services, such as buying a 
book through a web page. A company is more than a set of products and services, these involve facets of a nature as diverse as cultural, legal, technological, organizational, geographic, economic, strategic, among others [5-6].

Therefore, only having sufficiently consolidated knowledge can be implemented a set of principles and mechanisms that allow the sustainability of these new management models.

Thus, this article aims to contribute to characterize some of the relevant aspects that are the origin of the sustainability of dynamic logistics networks, seeking to find answers to the following questions:

- What is meant by the expression "the Enterprise $E_{i}$ trusts Enterprise $E_{j}$ ?

- What is the advantages of using statistical control charts for monitoring and control the trust levels of each of the dynamic logistics network members?

The paper is organized as follows. Section 2 describes the characteristics associated with trust. Section 3 presents a trust model for dynamic logistics networks. Section 4 presents some background about statistics process control needed to understand the authors' proposed approach. A case study is included in Section 5 to illustrate the application of the approach presented in the paper. Section 6 includes some concluding remarks.

\section{Trust Properties}

Based on the literature [7-10] can be identified a set of characteristics that are associated to trust, as following:

- Subjectivity - Trust reflects a subjective assessment of one enterprise in relation to other enterprises since different enterprises can assign different trust values to the same enterprise.

- Reduction of complexity - Under certain conditions trust can act as a mechanism to make processes more agile.

- Specific domain - The trust value is valid only in a specific domain. For each context under analysis, a trust value might be assigned to an enterprise. This means that an enterprise might have multiple trust values. As an example, the enterprise $E_{i}$ trust on the enterprise $E_{j}$ for the maintenance of an equipment but does not trust on its production capacity.

- Existence of memory - Various enterprises are able to identify past interactions in identical contexts with the same enterprises.

- Measurable - Trust can be measured through a scale where its limits are between total trust and total mistrust.

- Dynamics - The value of trust is dynamic and can increase or decrease. Its value depends on satisfaction degree resulting from past interactions among various enterprises.

- Nontransitive vs transitive - Trust itself is not transitive. As an example, if an enterprise $E_{i}$ trust on an enterprise $E_{j}$ and an enterprise $E_{j}$ trust on an enterprise $E_{k}$, it is not mandatory that the enterprise $E_{i}$ has to trust on the enterprise $E_{k}$. 
However, if we admit that enterprises can make recommendations to other enterprises, then, through a recommendation mechanism, trust becomes transitive provided that the following conditions are met:

- The enterprise $E_{j}$ explicit (recommend) the enterprise $E_{i}$ that trust in the enterprise $E_{k}$.

- The enterprise $E_{i}$ trust on the recommendations of enterprise $E_{j}$.

- The enterprise $E_{i}$ have the possibility to evaluate the recommendations issued by the enterprise $E_{j}$ without being subject to any kind of commitment.

\section{Trust Model for Dynamic Logistics Networks}

Considering that a dynamic logistics network can be understood as a cooperative process where the relations that are established are structured around social exchanges between the various agents (company - company relationship), which translate into transfer of resources, money flows, time, emotions, expectations and many other motivating elements, with the purpose of each of the enterprises seeking to achieve their business and / or social goals. Therefore, an enterprise only delegates a task to another enterprise when there is a trust threshold that compensates the risks.

Thus, in the proposed approach, the evaluation of the trust level of an enterprise $E_{j}$ is a function of the following dimensions:

- Competencies - The enterprise $E_{i}$ believes that the enterprise $E_{j}$ has the knowledge and technology necessary to produce a certain expected result that will play a determining role in the success of its objective.

- Capability - The enterprise $E_{i}$ believes that the enterprise $E_{j}$ has the necessary resources to ensure that a given result is achieved according to the specifications defined.

- Resilience - The enterprise $E_{i}$ believes that the enterprise $E_{j}$ has robust processes and redundant resources that ensure the production of a given result even if a set of unforeseeable events occur.

If $T_{E_{i j}, \text { task }_{m}}$ is designated as the enterprise trust value $E_{j}$ to perform a task task $_{m}$ it follows that:

$$
T_{E_{i j}, \text { task }_{i}}=C_{E_{i j}}\left(\operatorname{task}_{m}\right) \times C A P_{E_{i j}}\left(\operatorname{task}_{m}\right) \times R_{E_{i j}}\left(\operatorname{task}_{m}\right)
$$

where:

$T_{E_{i j}, \text { task }_{m}}$ - value associated with the trust assessment of the enterprise $E_{j}$ to perform a task $_{m}$; this value belongs to the range $[0 ; 1]$.

$C_{E_{i j}}\left(\operatorname{tas}_{m}\right)$ - value associated with the competencies evaluation of the enterprise $E_{j}$ involved in carrying out the task task $k_{m}$; this value belongs to the range $[0 ; 1]$. $C A P_{E_{i j}}\left(\right.$ task $\left._{m}\right)$ - value associated with the resources evaluation of the enterprise $E_{j}$ involved in carrying out the task task $k_{m}$; this value belongs to the range $[0 ; 1]$. 
$R_{E_{i j}}\left(\operatorname{tas}_{m}\right)$ - value associated with the resilience evaluation of the enterprise $E_{j}$ based on the processes and resources involved in carrying out the task task $k_{m}$; this value belongs to the range $[0 ; 1]$.

However, the existence of a positive trust value may not be sufficient for a given enterprise to trust on another enterprise to perform a particular task. Generally speaking, an enterprise $E_{i}$ with a task $t_{a s} k_{m}$ to carry out, can take one of the following options:

- Seek to accomplish the task by itself;

- Delegate to another enterprise $E_{j}$ the implementation of the task through a cooperation mechanism;

- Do nothing and give up the task.

In order to establish a logistics process between two enterprises it is necessary that there is a trust value that is acceptable to the enterprise that trust. Therefore, the following rule can be defined: When the trust value of an enterprise exceeds the Minimum Trust Value to Cooperate (MTVC), then the enterprise $E_{i}$ can delegate on the enterprise $E_{j}$ the execution of the task task $_{m}$.

Thus, the MTVC will play a role similar to the concept of lower specification limit (LSL) used in statistical quality control.

Although the determination of the minimum trust value is a subjective measure, in order to determine it, the following aspects must be taken into account:

- The enterprises, when they trust, delegate to another enterprise the performance of a certain task in order to seek to maximize their utility. The utility seeks to quantify in units of "useful" the gains that an enterprise $E_{i}$ obtain by performing a certain task task $_{m}$. Thus, the utility of an enterprise $E_{i}$ in the performance of a task $\operatorname{tas}_{m}$ in a certain time instant $t$ is represented by $U_{E_{i}}\left(\operatorname{tas}_{m}\right)_{t}$. On the other hand, by normalizing utility values, these may vary in the range comprised between 0 and 10 .

- Due to the difficulty in evaluating the impact of a task $\operatorname{task}_{m}$, the term importance should be considered, since the scenario in which there is a task with great utility and of reduced importance is equivalent to the scenario of a task with a reduced utility and of great importance. This variable play two distinct but complementary roles. In the first place, importance seeks to quantify in a subjective way the multiplier effect of the expected gains resulting from the performance of a certain task. In the meantime, the importance reflects the possibility that an enterprise can change its preferences according to the market changes that may occur. That is, for an enterprise $E_{i}$ the accomplishment of a task task $k_{m}$ in the past could be of high importance while its realization in the present may be of minor importance. The importance of performing a task $\operatorname{tas}_{m}$ to an enterprise $E_{i}$ at a given time $t$ is represented by $I_{E_{i}}\left(\operatorname{tas}_{m}\right)_{t}$. On the other hand, by normalizing the importance values, these can vary in the range between 0 and 10 .

In this context, the MTVC in the performance of a task will depend on the level of benefit associated with the task, that is, on the positive impact for an enterprise resulting from the accomplishment of a task, for the enterprise itself (self-benefit), or for another agent (benefit received), which can be measured in quantitative terms [11]. The quantification of benefits is given by the following equation: 


$$
B_{E_{i}}\left(\operatorname{task}_{m}\right)_{t}=U_{E_{i}}\left(\operatorname{task}_{m}\right)_{t} \times I_{E_{i}}\left(\operatorname{tas}_{m}\right)_{t}
$$

where:

$B_{E_{i}}\left(\operatorname{tas}_{m}\right)_{t}$-value of the Benefit associated with the enterprise $E_{i}$ resulting from the task $\operatorname{task}_{m}$

$U_{E_{i}}\left(\operatorname{tas}_{m}\right)_{t}$-value of Utility for enterprise $E_{i}$ associated with the task $\operatorname{tas}_{m}$

$I_{E_{i}}\left(\operatorname{task}_{m}\right)_{t}$-Importance level of task task $_{m}$ for the enterprise $E_{i}$

Therefore, using the decision theory, the options described above can be represented in a decision tree as shown in Figure 1. For the sake of simplicity and because of the option to do nothing and give up the task not be relevant to the analysis concerned, this option will not be considered.

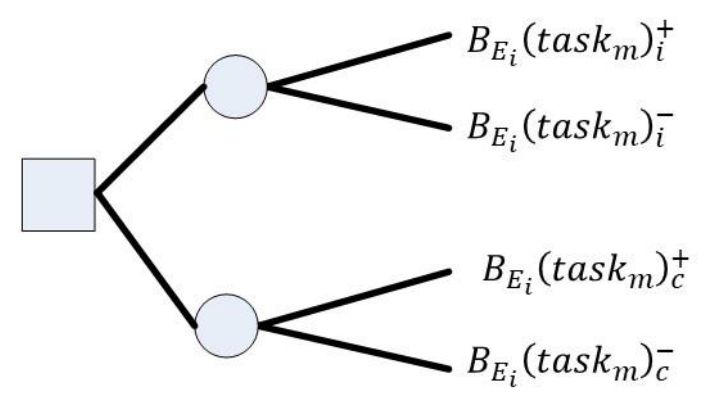

Figure 1 - Decision Tree

Where:

$B_{E_{i}}\left(\operatorname{tas}_{m}\right)_{i}^{+}$- benefit value of the enterprise $E_{i}$ successful in accomplishing the task task $_{m}$

$B_{E_{i}}\left(\operatorname{tas}_{m}\right)_{i}^{-}$- benefit value of the enterprise $E_{i}$ having failed to perform the task task $_{m}$

$B_{E_{i}}\left(\text { task } k_{m}\right)_{c}^{+}$- benefit value of the enterprise $E_{i}$ to be entrusted to complete the task task $k_{m}$, to another enterprise and the enterprise performed the task successfully;

$B_{E_{i}}\left(\operatorname{task}_{m}\right)_{c}^{-}$- benefit value of the enterprise $E_{i}$ to be entrusted to complete the task task $k_{m}$, to another enterprise and this made the task unsuccessful.

Thus, an enterprise $E_{i}$ should only entrust the performance of a task to another enterprise $E_{j}$ when:

$$
\begin{aligned}
& T_{E_{i}, E_{j}, \text { task }_{m}} \times B_{E_{i}}\left(\operatorname{task}_{m}\right)_{c}^{+}+\left(1-T_{E_{i}, E_{j}, \text { task }_{m}}\right) \times B_{E_{i}}\left(\text { task }_{m}\right)_{c}^{-} \geq T_{E_{i}, E_{i}, \text { task }_{m}} \times \\
& B_{E_{i}}\left(\text { task }_{m}\right)_{i}^{+}+\left(1-T_{E_{i}, E_{i}, \text { task }_{m}}\right) \times B_{E_{i}}\left(\text { task }_{m}\right)_{i}^{-}
\end{aligned}
$$

Then:

$$
T_{E_{i}, E_{j}, \text { task }_{m}} \geq T_{E_{i}, E_{i}, \text { task }_{m}} \times A+B
$$


where:

$$
\begin{array}{r}
A=\frac{B_{E_{i}}\left(\operatorname{task}_{m}\right)_{i}^{+}-B_{E_{i}}\left(\operatorname{task}_{m}\right)_{i}^{-}}{B_{E_{i}}\left(\operatorname{task}_{m}\right)_{c}^{+}-B_{E_{i}}\left(\operatorname{task}_{m}\right)_{c}^{-}} \\
B=\frac{B_{E_{i}}\left(\operatorname{task}_{m}\right)_{\bar{i}}^{-}-B_{E_{i}}\left(\operatorname{task}_{m}\right)_{c}^{-}}{B_{E_{i}}\left(\operatorname{task}_{m}\right)_{c}^{+}-B_{E_{i}}\left(\operatorname{task}_{m}\right)_{c}^{-}}
\end{array}
$$

$T_{E_{i}, E_{i}, \text { task }_{m}}$ - defines the self-trust that the enterprise $E_{i}$ has in the accomplishment of the task task $_{m}$.

In the case where the enterprise $E_{i}$ is not able to perform the task task $k_{m}$, except through a cooperative process, where the value of self-trust is null, $T_{E_{i}, E_{i}, \text { task }_{m}}=0$. Then, the MTVC is given as follows:

$$
T_{E_{i}, E_{j}, \operatorname{task}_{m}}>-\frac{B_{E_{i}}\left(\operatorname{task}_{m}\right)_{\bar{c}}^{\bar{c}}}{B_{E_{i}}\left(\operatorname{task}_{m}\right)_{c}^{+}-B_{E_{i}}\left(\operatorname{task}_{m}\right)_{c}^{\bar{c}}}
$$

As can be seen, the MTVC not only varies from enterprise to enterprise, as for the same enterprise, this value may vary depending on the task to be performed. For example, one of the factors that causes changes in the determination of the MTVC) is the relationship between $B_{E_{i}}\left(\operatorname{tas}_{m}\right)_{c}^{+}$and $B_{E_{i}}\left(\operatorname{tas} k_{m}\right)_{c}^{-}$. Therefore, the greater the value associated with failure $B_{E_{i}}\left(\operatorname{task}_{m}\right)_{c}^{-}$the bigger is the MTVC. In cases where the MTVC assumes a negative value, it means that trust is not a factor to be considered in the cooperation process.

\section{Statistical Process Control (SPC)}

All companies aim at the full satisfaction of their customers. This goal is achieved by increasing levels of trust between companies and their customers or business partners. Statistical methods play a key role in quality assessment, allowing, among other aspects, to evaluate whether a particular variable (product / service, process or other) completely satisfies the explicit needs, usually defined by a specification.

Statistical charts are valuable tools since they allow to distinguish between special causes and common causes of variation. The first developments were made by Shewhart [12]. However, in order to meet the demands of today's world, several authors have been developing various types of charts [13]. When it is possible to conveniently estimate the process parameters, SPC is developed in two stages, Phase I and Phase II. In this context, the following methodology is suggested:

Phase 1

Taking into account the literature in this phase, the Shewhart chart is most appropriate for each product/service or characteristic [13-14]. The upper control limit (UCL) and the lower control limit $(L C L)$ of these charts, as well as the central line $(C L)$, are determined through the formulas presented in Table 1. 
In the equations in Table 1 it is considered: $\bar{X}$ - average of the samples means; $\bar{R}-$ average of the range samples; $\bar{S}$ - average of the samples standard deviations; $\overline{M R}$ average of the moving ranges; being $A_{2}, A_{3}, B_{3}, B_{4}, D_{3}, D_{4}$ constants that depend on the sample size.

Table 1 - Control limits of Shewhart charts, in Phase 1 of SPC

\begin{tabular}{|c|c|c|c|}
\hline Chart & $L C L$ & $C L$ & $U C L$ \\
\hline $\bar{X}$ (sample mean) & $\overline{\bar{X}}-A_{2} \bar{R}$ ou $\overline{\bar{X}}-A_{3} \bar{S}$ & $\overline{\bar{X}}$ & $\overline{\bar{X}}+A_{2} \bar{R}$ ou $\overline{\bar{X}}+A_{3} \bar{S}$ \\
\hline $\begin{array}{c}R \text { (sample } \\
\text { range) }\end{array}$ & $D_{3} \bar{R}$ & $\bar{R}$ & $D_{4} \bar{R}$ \\
\hline $\begin{array}{c}S \text { (sample standard } \\
\text { deviation) }\end{array}$ & $B_{3} \bar{S}$ & $\bar{S}$ & $B_{4} \bar{S}$ \\
\hline$M R$ (moving range) & $D_{3} \overline{M R}$ & $\overline{M R}$ & $D_{4} \overline{M R}$ \\
\hline
\end{tabular}

Phase 2 - Monitoring

After checking the stability and analysing the process capacity, in Phase 1 of the SPC, statistical process control is continued through its monitoring. This procedure is commonly referred to as SPC Phase 2. It follows, in this Phase, the application of the control charts $Z$ and $W$, based on statistics $Z$ and $W$ calculated from statistics $\bar{X}$ (or $X$ ) and $S$ (or $R$, or $M R$ ), respectively. Shown in Table 2 are the transformed $Z$ and $W$ for the different charts. The control limits of the charts $Z$ and $W$ are shown in Table 3.

Table 2 - Statistics of $\mathrm{Z}$ and $\mathrm{W}$ charts

\begin{tabular}{|c|c|c|}
\hline$Z_{\bar{X}}$ and $W_{S}$ Chart & $Z_{\bar{X}}$ and $W_{R}$ Chart & $Z_{\bar{X}}$ and $W_{M R}$ Chart \\
\hline$\left(\mathrm{Z}_{\mathrm{p}}\right)_{\mathrm{E}_{\mathrm{j}}}=\left(\frac{\overline{\mathrm{X}_{\mathrm{p}}}-\mu}{\sigma_{\overline{\mathrm{X}}}}\right)_{\mathrm{E}_{\mathrm{j}}}$ & $\left(\mathrm{Z}_{\mathrm{p}}\right)_{\mathrm{E}_{\mathrm{j}}}=\left(\frac{\overline{\mathrm{X}_{\mathrm{p}}}-\mu}{\sigma_{\overline{\mathrm{X}}}}\right)_{\mathrm{E}_{\mathrm{j}}}$ & $\left(\mathrm{Z}_{\mathrm{p}}\right)_{\mathrm{E}_{\mathrm{j}}}=\left(\frac{X_{p}-\mu}{\sigma}\right)_{\mathrm{E}_{\mathrm{j}}}$ \\
\hline$\left(W_{p}\right)_{E_{j}}=\left(\frac{S_{p}}{\bar{S}}\right)_{E_{j}}$ & $\left(W_{p}\right)_{E_{j}}=\left(\frac{R_{p}}{\bar{R}}\right)_{E_{j}}$ & $\left(W_{p}\right)_{E_{j}}=\left(\frac{M R_{p}}{\overline{M R}}\right)_{E_{j}}$ \\
\hline
\end{tabular}

In the equations in Table 2 it is considered: $\left(\overline{X_{p}}\right)_{E_{j}}$ - sample trust mean $p$ for enterprise $E_{j} ; \mu_{E_{j}}$ - trust mean relative to domain X for enterprise $E_{j} ;\left(\sigma_{\bar{X}}\right)_{E_{j}}$ - standard deviation of the sample trust means distribution for enterprise $E_{j} ;\left(S_{p}\right)_{E_{j}}$ - sample standard deviation of the trust $p$ for enterprise $E_{j} ;\left(R_{p}\right)_{E_{j}}$ - sample range of the trust $p$ for enterprise $E_{j} ;\left(M R_{p}\right)_{E_{j}}$ - moving range of the trust $p$ for enterprise $E_{j}$; 
Table 3: Limits of control and centreline for $Z$ and $W$ charts

\begin{tabular}{|c|c|c|c|c|c|c|}
\cline { 2 - 7 } \multicolumn{1}{c|}{} & \multicolumn{2}{c|}{$Z_{\bar{X}}$ and $W_{S}$ Chart } & \multicolumn{2}{c|}{$Z_{\bar{X}}$ and $W_{R}$ Chart } & \multicolumn{2}{c|}{$Z_{\bar{X}}$ and $W_{M R}$ Chart } \\
\cline { 2 - 7 } \multicolumn{1}{c|}{} & $Z_{\bar{X}}$ & $W_{s}$ & $Z_{\bar{X}}$ & $W_{R}$ & $Z_{X}$ & $W_{M R}$ \\
\hline$U C L$ & 3 & $B_{4}$ & 3 & $D_{4}$ & 3 & $D_{4}$ \\
\hline$C L$ & 0 & 1 & 0 & 1 & 0 & 1 \\
\hline$L C L$ & -3 & $B_{3}$ & -3 & $D_{3}$ & -3 & $D_{3}$ \\
\hline
\end{tabular}

A relevant issue in the study of process performance in SPC Phase 2 is the definition of the periodicity of process capability analysis. Thus, it is suggested that this be done in real time, based on two normalized indexes $Z_{L}$ and $Z_{U}$ [14].

The analysis of the charts should reveal processes under statistical control, i.e. subject only to common causes of variation. The interpretation of Shewhart's charts is based on the existence of any non-random patterns, which may be detected by Norma ISO 8258:1991.

\section{Potential Application}

To illustrate the applicability of this methodology it is considered that there is a cluster of companies made up of four independent companies. Figure 2 shows the hypothetical matrix of competences.

\begin{tabular}{|c|c|c|c|}
\cline { 2 - 4 } \multicolumn{1}{c|}{} & $\mathrm{C} 1$ & $\mathrm{C} 2$ & $\mathrm{C} 3$ \\
\hline$E_{1}$ & $\mathrm{X}$ & & \\
\hline$E_{2}$ & & & $\mathrm{X}$ \\
\hline$E_{3}$ & $\mathrm{X}$ & $\mathrm{X}$ & \\
\hline$E_{4}$ & & $\mathrm{X}$ & $\mathrm{X}$ \\
\hline
\end{tabular}

Figure 2 - Competencies matrix

It is considered that, at a given moment, a customer $C l_{1}$ contact the company $E_{1}$ for the production of several units of the product $P$.

According to the planning carried out by the company $E_{1}$ for the production of the product $P$ the following competences are required:

$$
P=C_{1}+C_{2}+C_{3}
$$

For the sake of simplification, it is not considered the possibility of another alternative process, which, using other competences, would also allow obtaining the product $P$ with the same characteristics / functionalities.

Taking into account the defined context, the company $E_{1}$ will take a set of decisions and define the MTVC for each competency and for each of the companies, as shown in Figure 3. 


\begin{tabular}{|c|c|c|c|c|}
\cline { 3 - 4 } \multicolumn{2}{c|}{} & \multicolumn{3}{c|}{ MTVC } \\
\hline Competencies & Decision & $E_{2}$ & $E_{3}$ & $E_{4}$ \\
\hline $\mathrm{C} 1$ & Use internal resources & ---- & ---- & --- \\
\hline $\mathrm{C} 2$ & $\begin{array}{c}\text { Need for cooperation for not compromise other } \\
\text { objectives }\end{array}$ & & 0,6 & 0,7 \\
\hline $\mathrm{C} 3$ & Need for cooperation by not having C3 & 0,5 & & 0,6 \\
\hline
\end{tabular}

Figure 3 - Decisions of company $E_{1}$

In view of the decisions taken, the company $E_{1}$, recognizing the need for cooperation, announces, within the cluster, its needs in the competencies $C 2$ and $C 3$.

In order to select, at each moment, the best solution, i.e., the company that offers the best collaborative guarantees to the company $E_{1}$, the values of the level of trust that each company presented for the competences enunciated, $C 2$ and $C 3$ were determined during 15 periods. Considering the prior knowledge of trust of the companies $E_{2}, E_{3}$ and $E_{4}$ (i.e., the mean value and the dispersion value of each company for competencies $C 2$ and $C 3$, estimated values in the preliminary phase (Phase 1) of the statistical analysis of companies' processes) and based on the values of business trust at each moment, $Z$ control charts were built to monitor the level of trust and performance of companies. The statistics that allow the construction of the charts are determined by the equations presented in Table 2.

These charts allow monitoring the trust level of companies in relation to competencies $C 2$ and $C 3$. This monitoring consists of verifying the stability of the processes (checking whether the standard of competence trust level is random) and detecting the existence of anomalous situations, characterized by values of the $Z$ statistic that correspond to points outside the control limits of the chart. In addition, it was calculated the capability indices $Z_{L}$. This indicator, for a given competence $(C 2$ and $C 3$ ), gives indication of the suitability of each company to satisfy the minimum required level of trust.

The decision on the choice of the company to cooperate with the company $E_{1}$, for the period $p+1$, is taken on the basis of the information in the period $p$. The following criteria are established for the selection of the company that will collaborate with the company $E_{1}$ :

1. Choose the company that has the highest absolute value of $Z_{I}$.

2. When the standard of trust of an enterprise presents special causes of variation (outside statistical control), it should not be selected for the next two instants (instants $p+1$ and $p+2$ ).

Figure 4 shows the trust monitoring of companies $E_{3}$ and $E_{4}$ for the competence $C 2$. 


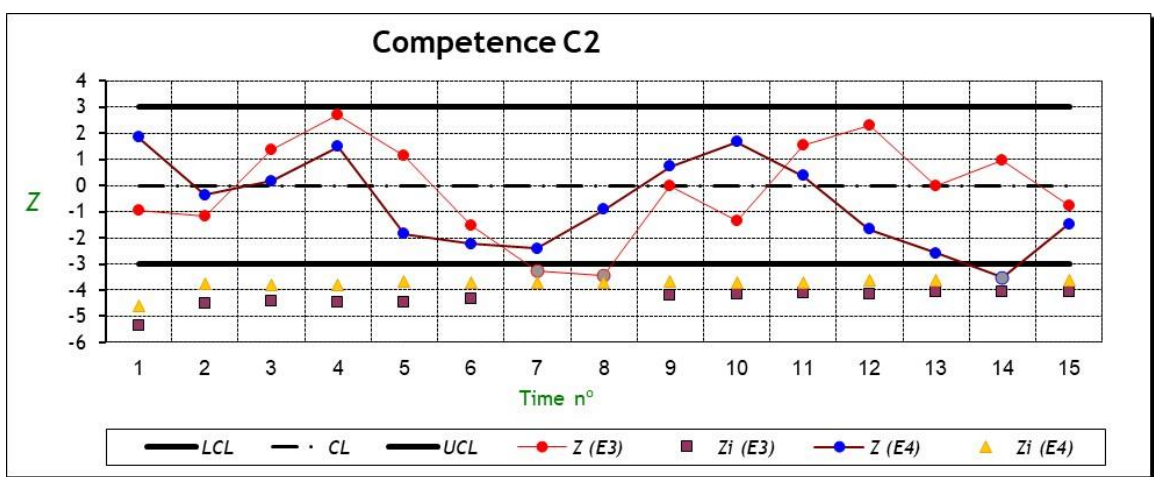

Figure 4 - Capability monitoring and analysis for the competence $C 2$ of companies $E_{3}$ and $E_{4}$

The analysis of Figure 4 leads to the following conclusions:

- Initially one should invest in partnership with the company $E_{3}$ (better value of $\left.Z_{L}\right)$, up to period 7 ( $1^{\circ}$ criterion);

- For the company $E_{3}$, there are special causes in period 7 and period 8; thus, one should opt for the partnership with the company $E_{4}$ for periods 8,9 and $10\left(2^{\circ}\right.$ criterion).

- From the 11th period, since the company $E_{3}$ has a better value of $Z_{L}$ than the company $E_{4}$, one should opt for the partnership with the company $E_{3}$.

- To register a special cause in period 14 , referring to the company $E_{4}$, which does not influence the decision due to better value of $Z_{L}$ for company $E_{3}$.

It is presented in Figure 5 the trust monitoring of companies $E_{3}$ and $E_{4}$ for the competence $C 3$. The analysis of Figure 5 leads to the following conclusions:

- The processes relating to companies $E_{2}$ and $E_{4}$ (competence $C 3$ ) are stable, i.e., there are no special causes of variation; so the decision on the choice of the company to cooperate with the company $E_{1}$ should be taken solely on the basis of the $1^{\circ}$ criterion;

- Initially one should invest in partnership with the company $E_{2}$ (better value of $Z_{L}$ ) up to period 10 .

- For periods 11 and 12 , since the values of $Z_{L}$ for companies $E_{2}$ and $E_{4}$ are similar, the choice is indifferent, being the decision made based on other indicators in place of the level of trust;

- For the period 13 and following, one should opt for the partnership with the company $E_{4}$ (better value of $Z_{L}$ ). 


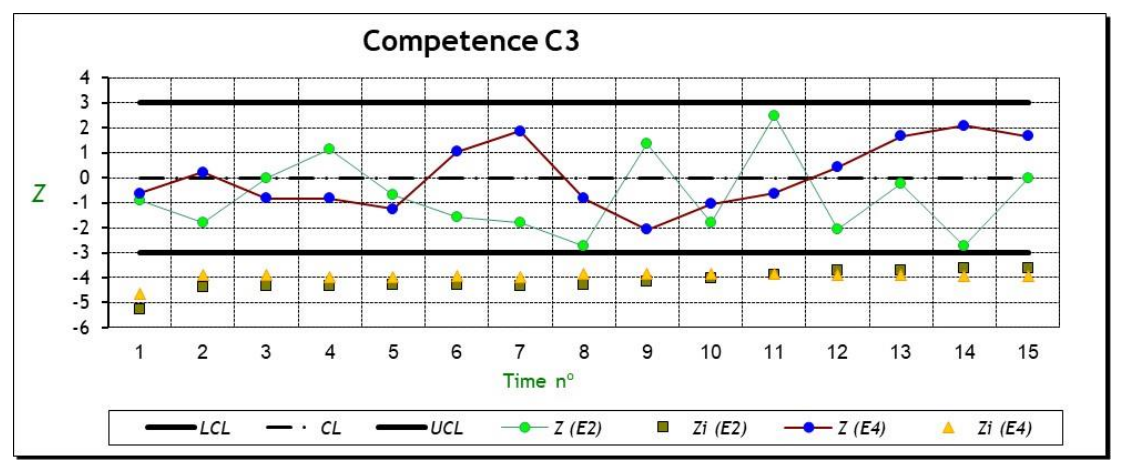

Figure 5 - Capability monitoring and analysis for the competence $C 3$ for companies $E_{2}$ and $E_{4}$

With regard to competencies $C 2$ and $C 3$, the table presented in Figure 6 summarizes the decision-making regarding the company that should be selected to collaborate with the company $E_{1}$.

\begin{tabular}{|c|c|c|c|c|c|c|c|c|c|c|c|c|c|c|c|}
\hline Competence & 1 & 2 & 3 & 4 & 5 & 6 & 7 & 8 & 9 & 10 & 11 & 12 & 13 & 14 & 15 \\
\hline $\mathrm{C} 2$ & $E_{3}$ & $E_{3}$ & $E_{3}$ & $E_{3}$ & $E_{3}$ & $E_{3}$ & $E_{3}$ & $E_{4}$ & $E_{4}$ & $E_{4}$ & $E_{3}$ & $E_{3}$ & $E_{3}$ & $E_{3}$ & $E_{3}$ \\
\hline $\mathrm{C} 3$ & $E_{2}$ & $E_{2}$ & $E_{2}$ & $E_{2}$ & $E_{2}$ & $E_{2}$ & $E_{2}$ & $E_{2}$ & $E_{2}$ & $E_{2}$ & & & $E_{4}$ & $E_{4}$ & $E_{4}$ \\
\hline
\end{tabular}

Figure 6 - Decision-making on the collaborative process with companies $E_{2}, E_{3}$ and $E_{4}$ (choice of the company to collaborate with $E_{1}$, by period), concerning the competences $C 2$ and $C 3$

\section{Conclusions}

There seems to be a clear consensus that companies to survive have increasingly to establish "working together" relationships with other companies. In this context, the role of trust was discussed and a model was proposed to measure the level of trust between the various companies as support for the development of dynamic logistics networks.

The methodology proposed for the monitoring of trust presents a number of advantages that stand out: the perception of the evolution of the trust level of a company is possible using statistical techniques such as the control charts; the application of dimensionless charts $Z$ is a good tool to verify the stability of the standard referring to the trust level of the companies under study, allowing in real time the monitoring of the standard that a certain company displays regarding the trust level.

The ability of a company to demonstrate a given competence is evidenced by an indicator, more specifically the capability index. 
Decision-making based on statistical techniques such as those presented in this article, is more rigorous, avoiding in this way the subjectivity of analysis.

However, it is necessary to develop an application in real context in order to validate not only the proposed trust model, but also the application of statistical quality control in the trust monitoring.

\section{Acknowledgments}

This work was funded in part by the Center of Technology and Systems of Uninova and the Portuguese FCT-PEST program UID/EEA/00066/2013. And, it was also partially supported by FCT, through IDMEC, under LAETA, project UID/EMS/50022/2013.

\section{References}

1. Abreu, A.; Camarinha-Matos, Luis M. An approach to measure social capital in collaborative networks. In: Adaptation and Value Creating Collaborative Networks, IFIP AICT Series 362/2011, Springer: Berlin Heidelberg, pp. 29-40.

2. Verdouw, C. N., Wolfert, J., Beulens, A. J. M., \& Rialland, A. (2016). Virtualization of food supply chains with the internet of things. Journal of Food Engineering, 176, 128-136.

3. Simatupang, T. M., \& Sridharan, R. (2002). The collaborative supply chain. The international journal of logistics management, 13(1), 15-30.

4. Jasti, N. V. K., \& Kodali, R. (2015). A critical review of lean supply chain management frameworks: proposed framework. Production Planning \& Control, 26(13), 1051-1068.

5. Abreu, A.; Camarinha-Matos, Luis M. On the role of value systems and reciprocity in collaborative environments. In: Working Conference on Virtual Enterprises. Springer, Boston, MA, 2006. p. 273-284.

6. Abreu, A.; Camarinha-Matos, L. M.: "Understanding Social Capital in Collaborative Networks", in Balanced Automation Systems for Future Manufacturing Networks - IFIP AICT 322 Á.O. Bas., R.D. Franco., and P.G. Gasquet, Editors. 2010, Springer. p. 109 - 118.

7. Axelroad, R., The Evolution of Cooperation. 1984: Basic Books

8. Castelfranchi, C. and R. Falcone. Trust is much more than subjective Probalility: Mental components and sources of trust. in Proceedings of the 33rd Hawaii International Conference on Systems Sciences (HICSS 2000). 2000. Maui, Hawaii, USA

9. Gambetta, D., Can We Trust Trust? Trust: Making and Breaking Cooperative Relations, electronic edition, Department of Sociology, University of Oxford, 2000, 213-237.

10. D. Chen, G. Chang, D. Sun, J. Li, J. Jia, and X. Wang, "TRM-IoT: A Trust Management Model Based on Fuzzy Reputation for Internet of Things," Computer Science and Information Systems, vol. 8, no. 4, Oct. 2011, pp. 1207-1228.

11. Camarinha-Matos, L.M. and A. Abreu, A contribution to understand collaboration benefits, in: Emerging Solutions for Future Manufacturing Systems, Springer, IFIP AICT Vol. 159, pp. 287-298, Sep 2004.

12. Shewhart W. A. Economic Control of Quality of Manufactured Product, D. Van Nostrand Company, Inc, New York, 1931

13. Montgomery, Douglas C. Introduction to statistical quality control. John Wiley \& Sons, 2007.

14. Pereira Z. L; Requeijo J. G. Qualidade: Planeamento e Controlo Estatístico de Processos, Co-edição da Fundação da FCT/UNL e da Editora Prefácio, Lisboa, 2008. 